\title{
Dock5 is a new regulator of microtubule dynamic instability through GSK3 $\beta$ inhibition in osteoclasts
}

Sarah Guimbal $^{1,2, \pi}$, David Guérit ${ }^{1,2}$, Manon Chardon ${ }^{1,2}$, Anne Blangy $^{1,2,}$, Virginie Vives $^{1,2}$

${ }^{1}$ Centre de Recherche de Biologie Cellulaire (CRBM), CNRS UMR 5237, 1919 route de Mende, 34293 Montpellier cedex 5, France.

${ }^{2}$ Montpellier University, 34095 Montpellier cedex 5, France.

"Present address : INSERM U1034, 1 avenue de Magellan, 33604 Pessac, France

Correspondence and requests for materials should be addressed to A.B. (email: anne.blangy@crbm.cnrs.fr).

Running title: Dock5 regulates microtubule dynamics in osteoclasts 


\section{Abbreviation Meaning}

APC

Adenomatous polyposis coli

BMM

Bone Marrow Macrophages

GSK3 $\beta$

Glycogen Synthase Kinase 3 beta

HDAC6

Histone Deacetylase 6 


\section{Abstract}

Background information: Osteoclast resorption is dependent on a podosome-rich structure, called sealing zone, which is stabilized by acetylated microtubules. It tightly attaches the osteoclast to the bone creating a favorable acidic microenvironment for bone degradation. We already established that Rac activation by Dock5 is necessary for osteoclast resorption. Indeed, inhibition of Dock5 in osteoclasts results in Rac1 decreased activity associated to impaired podosome assembly into sealing zones and resorbing activity.

Results: In this report, we show that Dock5 knockout osteoclasts also present a reduced acetylated tubulin level leading to a decreased length and duration of microtubule growth phases whereas their growth speed remains unaffected. Dock5 does not act by direct interaction with the polymerized tubulin but through inhibition of the microtubules destabilizing kinase GSK3 $\beta$ downstream of Akt activation. Interestingly, we ruled out the implication of Rac1 in this process using specific inhibitors.

Conclusion: Our data involve Dock5 as a new regulator of microtubule dynamic instability in osteoclast.

Significance: The fact that Dock5 is a regulator of both actin cytoskeleton and microtubule dynamics makes it an interesting therapeutic target for osteolytic pathologies because of its dual role on sealing zone formation and stabilization.

Keywords: Dock5, osteoclast, microtubule, knockout mice, resorption 


\section{Introduction}

Bone homeostasis is regulated through life by the balanced actions of highly specialized bone-forming osteoblasts and bone-resorbing osteoclasts. An important step of bone resorption is mineral phase dissolution by massive secretion of $\mathrm{H}^{+}$and $\mathrm{Cl}^{-}$ions. It exposes the collagen-rich underlying organic phase that becomes accessible to degradation by lysosomal proteases such as cathepsin K (Cappariello et al., 2014). To maintain this acidic microenvironment which is the key for an efficient resorption, osteoclasts tightly attach to the bone matrix by an actin-rich sealing zone composed of densely packed podosomes. Because of its nature, it was thought for a long time that its formation depended only on actin regulators whose roles have been extensively studied (Lowe et al., 1993) (Chellaiah et al., 2000) (Calle et al., 2004) (Destaing et al., 2008) (Croke et al., 2011) (Touaitahuata et al., 2014). A decade and a half ago, Jurdic's lab discovery that an intact microtubule network was necessary for this adhesion structure stability (Destaing et al., 2003) emphasized the importance to understand the signaling pathways linking both cytoskeletons. On one hand, it was shown that belt stabilization is correlated to microtubule acetylation which is maintained by downregulation of two important players. First, RhoA-mDia2 dependent tubulin deacetylase HDAC6 activity (Destaing et al., 2005) is negatively controlled by Pyk2 (Gil-Henn et al., 2007). Independently, HDAC6 interaction with tubulin is antagonized by competitive binding of $\mathrm{Cbl}$ adaptor proteins (Purev et al., 2009). Second, the kinase GSK3 $\beta$ activity is inhibited by serine 9 phosphorylation by Akt. It allows stabilizing MAPs binding to growing microtubules (Matsumoto et al., 2013) and interaction between + TIP EB1 and actin belt associated cortactin (Biosse Duplan et al., 2014). On the other hand, it was shown that microtubules stabilize sealing zones through direct linkage mediated by actin regulators. Indeed, the unconventional myosin $X$ encircles nascent sealing zones and provides force to expand them into mature expanded ones through interaction with microtubules (McMichael et al., 2010). More, the Dynamin 2 GTPase acts as an adaptor molecule between microtubules and actin podosomes, preventing them to scatter from the densely packed adhesion structure (Batsir et al., 2017). We showed that the Dock family member Dock5 is an exchange factor for the actin regulator Rac1 (Vives et al., 2011) (Ferrandez et al., 2017). During osteoclast resorption cycle, av $\beta 3$ integrins signaling induces Dock5 recruitment to the Src/Pyk2/p130Cas complex which ultimately leads to Rac1 activation and localization to the sealing zone (Vives et al., 
2011) (Nagai et al., 2013). Dock5 plays an important role in this pathway because its deletion in knockout mice results in increased trabecular bone mass due to an impaired osteoclasts ability to assemble podosomes into sealing zones (Vives et al., 2011), a phenotype also observed in knockout mice for Rac1 (Croke et al., 2011) (Magalhaes et al., 2011) and its guanine exchange factors (Faccio et al., 2005) (Takegahara et al., 2010). Interestingly, a group working on allergy showed that Dock5 is essential for the dynamic rearrangement of microtubules during mast cell degranulation in anaphylactic responses (Ogawa et al., 2014).

In this study, we tested the hypothesis that Dock5 could play a central part in the control of osteoclast adhesion structure establishment through not only Rac1dependent assembly (Vives et al., 2011) but also Rac1-independent formation/stabilization. We showed that Dock5 is indeed involved in sealing zone stabilization through microtubules dynamic instability regulation via the Akt-GSK3 $\beta$ pathway.

\section{Results}

\section{Dock5 $^{-/-}$osteoclasts present an abnormal microtubule acetylation pattern} associated to a perturbed microtubule dynamic instability

Western blot analysis of proteins from wild-type and Dock5 knockout osteoclasts showed a significant decrease of tubulin acetylation in the absence of Dock5 (figure 1A). Confocal immunofluorescence microscopy allowed us to take a closer look at the microtubules distribution and acetylation pattern (figure 1B). As expected (Akisaka et al., 2011), microtubules of wild-type osteoclasts were typically organized (i) radially from the perinuclear region to the periphery where the podosome belt was located and (ii) circularly at the periphery. Both were modified with large evenly distributed acetylation patches. Although Dock5 ${ }^{-/-}$osteoclasts microtubules kept the radial orientation, the circular ones were missing at the periphery, which was consistent with the absence of podosome assembly into a belt. More, tubulin acetylation, that was present in small patches, was decreased in density compared to their wild-type counterpart (figure 1C).

Since tubulin acetylation is associated with microtubule stabilization (Matsumoto et al., 2013), we reasoned that this acetylation defect could affect their dynamic instability. To answer this question, we expressed the EB3 +TIP fused to 
GFP in wild-type and Dock5 knockout osteoclasts to visualize their growing microtubule plus ends using time-lapse video microscopy (supplementary figure 1). Tracking of EB3-GFP at the +TIP of microtubules (figure 2A) showed a significant decrease of microtubule polymerization duration (figure 2B) and length (figure 2C) in the absence of Dock5. Polymerization speed however remained unchanged (figure 2D). More, the mean total number of actively growing microtubules was similar for both genotypes per image of the movies (figure 2E) but the total comet tracks number was significantly increased in Dock $5^{-/-}$osteoclasts over a 1 min period (figure 2F), suggesting an increased number of catastrophes.

\section{Dock5 regulates microtubules dynamics through a Rac-independent pathway}

It has been shown that Dock5 is a guanine exchange factor for Rac1 whose activity is decreased in Dock5 knockout osteoclasts (Vives et al., 2011). That made us wonder if the microtubule phenotype we described in Dock $5^{-/}$osteoclasts was Rac-dependent. We reasoned that, if it is the case, we should reproduce it when we specifically inhibit Dock5-dependent Rac activation in wild-type osteoclasts. Western blot analysis showed that, opposite to what was observed in Dock5 knockouts, treatment with an allosteric inhibitor of Dock5 called C21 (Vives et al., 2011) (Vives et al., 2015) (Ferrandez et al., 2017) (Xu et al., 2017a) significantly increased tubulin acetylation level (figure $3 \mathbf{A}$ ). It was confirmed by confocal immunofluorescence microscopy that showed that, in addition to the podosome belt disruption, C21 treatment induced a more intense microtubules acetylation compared to wild-type osteoclasts (figure 3B). As expected, we observed the same phenotype using EHT 1864, a compound that prevents Rac guanine nucleotide association and consequently inhibits downstream signaling (Shutes et al., 2007). Indeed, tubulin acetylation augments with increasing concentrations of the drug in osteoclasts (figure 4A) that show a disrupted microtubule network (figure 4B). In order to check if the acetylation alteration affected microtubules dynamics, we treated or not EB3GFP expressing wild-type osteoclasts with $\mathrm{C} 21$ and recorded the resulting comets using time-lapse video microscopy. Their tracking showed a significant decrease of microtubule polymerization duration, length and speed after C21 treatment (figure 3C). More, C21 impacted neither the total number of actively growing microtubules on each image of the movies (supplementary figure 2A) nor the comet tracks number over a $1 \mathrm{~min}$ period (supplementary figure 2B). These results show that 
actin belt disruption following the complete (EHT 1864) or partial (C21) inhibition of Rac activity does not reproduce the microtubule phenotype observed in Dock5 knockouts. It suggests that Dock5 regulates microtubules independently of its Rac guanine exchange factor activity in osteoclast.

\section{Dock5 regulates microtubules through a distant signaling pathway.}

Consistently with its Rac-activating role, we previously showed that Dock5 colocalizes with vinculin, an actin cloud-associated protein, at the podosome belt in RAW264.7 cell-derived osteoclasts (Vives et al., 2011). Since we uncovered a new microtubule-regulating function, we wondered whether a Dock5 protein fraction could also be associated to microtubules. To answer this question, we separated soluble and polymerized microtubules. Western blot analysis showed that Dock5 was not associated to the polymerized fraction, which contained acetylated tubulin and could be depolymerized upon nocodazole treatment (figure $\mathbf{5 A}$ ). These results suggest that Dock5 microtubules regulation is not mediated by direct association but through a distant signaling pathway.

\section{Dock5 ${ }^{-/}$osteoclasts show an increased GSK3 $\beta$ activity}

In order to identify the mechanism by which the microtubules were destabilized in Dock5 knockouts, we searched for deregulations of pathways involved in microtubules acetylation in osteoclasts. HDAC6 is a deacetylase whose activity is kept to a minimum (Gil-Henn et al., 2007) (Purev et al., 2009) to allow a stable microtubule network. We therefore checked whether HDAC6 activity was higher Dock $5^{-/}$osteoclasts but we could not find any differences between genotypes (figure 5B). We next focused on the Akt-GSK3 $\beta$ axis. Akt inhibits GSK3 $\beta$; a serine threonine kinase GSK3 $\beta$ which destabilizes microtubules by regulating microtubules associated proteins interactions (Matsumoto et al., 2013). Western blot analysis of GSK3 $\beta$ inhibitory serine 9 phosphorylation showed that GSK3 $\beta$ activity was increased in Dock $5^{-/}$osteoclasts (figure $5 \mathrm{C}$ ). Interestingly, Akt activity was not modified (figure 5D), suggesting that Dock5 acts downstream in this pathway.

Mature Dock5 $5^{-/}$osteoclasts mainly present isolated or clustered podosomes as if they were not able to assemble or maintain them into a belt (Vives et al., 2011). Since acetylated microtubules were shown to be necessary for podosome belt 
assembly/stabilization (Destaing et al., 2003) (Destaing et al., 2005), we assumed that restoration of a normal acetylation level in Dock $5^{-/-}$osteoclasts would rescue the actin belt. Therefore, wild-type and Dock5 knockout osteoclasts were cultured in the presence of GSK3 $\beta$ inhibitor lithium chloride. Although the treatment increased tubulin acetylation at a similar level between the two genotypes, it was not enough to allow the actin belt formation/stabilization in the absence of Dock5 (figure 5E). The same result was obtained using CHIR99021, a more selective GSK3 $\beta$ inhibitor (data not shown).

There is a close relationship between microtubules and the actin cytoskeleton in osteoclasts. Microtubules grow toward isolated/clustered podosomes during osteoclast differentiation and then form a ring at the cell periphery where the podosome belt is located (Akisaka et al., 2011). During this process, they are necessary for podosomes transition from rings to belt (Destaing et al., 2003). To our knowledge, no data have been made available about the microtubule network in mice knockout for actin regulators, but we would expect an effect on the microtubules dynamics. Since the actin regulator Rac activity is also decreased in Dock $5^{-/-}$ osteoclasts (Vives et al., 2011), we decided to reestablish not only GSK3 $\beta$ inhibition but also Rac activation hypothesizing that both might be needed for a wild-type podosome belt formation/stabilization. Contrary to our expectations, lithium chloride treatment of Rac L61 infected knockout osteoclasts did not rescue the phenotype (data not shown). However, we cannot exclude the fact that a better controlled regulation of Rac activation level and/or localization is important for this process.

\section{Discussion}

Osteoclast resorption function depends on podosome assembly into sealing zones. More and more evidence show now that the interplay between the actin cytoskeleton and microtubules is crucial for this adhesion structure formation/stabilization but the overall mechanism is still poorly understood. We already established that Dock5 is essential for sealing zones formation through Racdependent actin regulation. In this report, we show that Dock5 might also be involved in its stabilization by controlling microtubule dynamic instability in a Rac-independent pathway. Dock5 deletion results in decreased microtubules growth length and duration associated to reduced acetylated tubulin level. This post translational 
modification is a hallmark of stability because it increases mechanical resilience to ensure the persistence of long-lived microtubules (Xu et al., 2017b) (Janke and Montagnac, 2017). Its downregulation, resulting from either HDACs inhibition or GSK3 $\beta$ activation, has been correlated to microtubule dynamics alteration in different cell types (Garza et al., 2018) (Bacon et al., 2015) (Qu et al., 2017).

Dock5 belongs to the Dock family of guanine nucleotide exchange factors which are atypical activators of small $G$ proteins through evolutionarily conserved DHR2 domain (Laurin and Côté, 2014). Accordingly, Dock5 published functions are mainly related to Rac activation (Omi et al., 2008) (Vives et al., 2015) (Vives et al., 2011) (Ferrandez et al., 2017) (Biswas et al., 2019) in various cellular processes such as neutrophil chemotaxis and superoxide production(Watanabe et al., 2014), epithelial cell invasion and metastasis (Frank et al., 2017) or lens protection (Xu et al., 2017a) (Omi et al., 2008). Ogawa et al. were the first ones to describe a Racindependent role in microtubule network remodeling during mast cell degranulation. In these cells, Dock5 acts as a key signaling adaptor that brings Akt into the vicinity of GSK3 $\beta$, allowing it to phosphorylate GSK3 $\beta$ on serine 9 and inhibit its activity (Ogawa et al., 2014). The fact that Akt activation remains unchanged whereas that of GSK3 $\beta$ is increased in Dock5 knockout osteoclasts suggests that the same mechanism takes place in both cell types. Ubiquitously-expressed serine threonine kinase GSK3 $\beta$ is a critical negative regulator of microtubule dynamic instability (Xu et al., 2015) (Kumar et al., 2009) (Barnat et al., 2016). It phosphorylates microtubulebinding proteins such as MAP1B (Barnat et al., 2016), CRMP-2 (Liz et al., 2014) (Garza et al., 2018), CLASP-2 (Kumar et al., 2009) (Schmidt et al., 2012), Tau (Xu et al., 2015) (Gąssowska et al., 2014) or APC (Asada and Sanada, 2010) (Zhou et al., 2004), preventing them from stabilizing microtubules. Some of them are recruited by EB1 at growing microtubule ends that can be assimilated to a molecular platform establishing the link between microtubules and other structures (Akhmanova and Steinmetz, 2015). In osteoclasts, EB1 is enriched in microtubules that are directed toward podosomes (Akisaka et al., 2011). Depletion of Akt results in EB1/APC loss of interaction leading to reduced sealing zone and bone resorption, which are recovered upon GSK3 $\beta$ inhibition (Matsumoto et al., 2013). More, EB1 which is indispensable for podosome patterning, interacts with podosome-containing acetylated cortactin in the belt (Biosse Duplan et al., 2014). It would be interesting to test if either one of 
these proteins phosphorylation status or localization is impacted in the absence of Dock5.

Our observations strongly suggest that Dock5 is necessary for osteoclast adhesion structure establishment by stimulating dual pathways: Rac1-dependent podosome formation/patterning and Rac1-independent stabilization via Aktdependent GSK3 $\beta$ inhibition (figure 6). In the absence of Dock5, decreased Rac activation and GSK3 $\beta$ inhibition are observed. Since both are involved in podosome belt formation and stabilization respectively, we were surprised that a simultaneous recovery of their physiological levels could not rescue podosome belts in Dock $5^{-/-}$ osteoclasts. This process might need a finely tuned amount of Rac activation and/or localization that can hardly be achieved though primary cells infection. Similarly, although lithium chloride treatment increases in fine microtubule acetylation level, the latter is much higher than in control osteoclasts (figure 5E). That might affect the expected rescue because both positive and negative regulation of acetylation impact microtubules growth characteristics (Qu et al., 2017) (Zilberman et al., 2009). Nevertheless, further data are consistent with our model. Among them, the fact that partial (C21) or complete (HT 1864) inhibition of Rac1 activity did not reproduce Dock $5^{-/}$osteoclasts phenotype suggesting that at least part of it is independent from this GTPase. In the same line of idea, since Rac1 signaling pathway has been shown to downregulate Op18 catastrophe promoting activity through its phosphorylation (Watabe-Uchida et al., 2006) (Wittmann et al., 2004), we wondered whether Op18 phosphorylation levels were decreased in Dock $5^{-/-}$osteoclasts which show a reduced Rac activity (Vives et al., 2011). Interestingly, they were not modified by the absence of Dock5 expression in osteoclasts (unpublished data). Dock5 is not the only member of the Dock family to regulate microtubules independently from its guanine exchange factor activity. Dock7 controls the genesis of neurons from radial glial progenitor cells during cortical development through antagonistic interaction with the microtubule growth-promoting function of TACC3 (Yang et al., 2012). And finally, Dock3 participates in BDNF-dependent primary hippocampal neurons axonal outgrowth by also regulating (i) Rac1-dependent actin reorganization and (ii) microtubule assembly through GSK3 binding, recruitment to the plasma membrane and inactivation. The resulting decrease in CRMP-2 and APC phosphorylation allows their association to tubulin dimers and promotes microtubules polymerization (Namekata et al., 2012). 
Altogether, our data involve Dock5 as a new regulator of microtubule dynamic instability in osteoclast making it is an interesting therapeutic target for osteolytic pathologies because of its dual role on sealing zone formation/patterning and stabilization.

\section{Materials and Methods}

Ethics statement

Mice sacrifice and bone marrow harvest were performed in compliance with local animal welfare laws, guidelines and policies, according to the rules of the regional ethical committee.

Reagents.

C21 (N-(3,5-dichlorophenyl)-benzenesulfonamide) was synthetized by Roowin, lithium chloride was purchased from Fluka (\#62476), EHT1864 from Santa Cruz (\#sc361175) and nocodazole from Sigma (\#M1404).

Bone Marrow Macrophages (BMMs) isolation and differentiation in osteoclasts Bone marrow cells were purified from long bones of 6- to 8- week-old C57BL/6 Dock5 wild-type and knockout mice sacrificed by cervical dislocation. $3.10^{6}$ bone marrow cells were cultured for 3 days in $\alpha$ MEM containing $10 \%$ heat-inactivated fetal calf serum (Biowest), $2 \mathrm{mM}$ glutamine and 100U/ml penicillin-streptomycin supplemented with $100 \mathrm{ng} / \mathrm{ml}$ M-CSF (Miltenyi, \#130-101-703) in 100mm-diameter petri dishes. Medium was changed and the cells cultured for another 3 days to obtain BMMs. For osteoclast differentiation, 3.10 $\mathrm{BMMs} /$ well were seeded in 24-well tissue culture plates and cultured with $30 \mathrm{ng} / \mathrm{ml}$ M-CSF and $50 \mathrm{ng} / \mathrm{ml}$ RANKL (Miltenyi, \#130-094076) for 4-6 days. Media was changed every 2 days.

Retroviral infection of BMMs

pMXS-EB3-GFP or pMXS-Rac L61-GFP was co-transfected with pC57GP-Gag-pol and pCSIG-VSV-G constructs into Hek 293T cells using Jet-PEI (Polyplus transfection, \#101-10 N). Six hours later, the medium was replaced with fresh one and cells were grown for an additional $72 \mathrm{~h}$. The conditioned medium containing recombinant retroviruses was collected and filtered through $0.45 \mu \mathrm{m}$-pore-size filters. 
BMMs were cultured with fresh retroviral supernatant diluted to half in $\alpha M E M$ containing 10\% fetal calf serum, $2 \mathrm{mM}$ glutamine, $8 \mu \mathrm{g} / \mathrm{ml}$ polybrene (Sigma) and 100 $\mathrm{ng} / \mathrm{ml} \mathrm{M}-\mathrm{CSF}$ for $24 \mathrm{~h}$ and then selected for expression of the construct with $3 \mu \mathrm{g} / \mathrm{ml}$ puromycin (Sigma) for $24 \mathrm{~h}$. Puromycin-resistant BMMs were used for osteoclast differentiation.

Time-lapse microscopy and microtubules dynamic instability analysis

EB3-GFP expressing osteoclasts were placed on a $37^{\circ} \mathrm{C}$ heated stage in a $5 \% \mathrm{CO}_{2}$ chamber. Images were acquired using a Yokogawa CSU-X1 spinning-disk confocal unit (Andor Technology) and an EMCCD iXon Ultra camera coupled to a Nikon Ti Eclipse microscope (Nikon Instruments) controlled by the Andor iQ3 software (Andor Technology). They were collected every second after 488-nm laser illumination using a 60X plan apo lambda 1.4 NA objective over a 2 min period and processed using ImageJ PureDenoise plugin. EB3-GFP comets appearing in at least 3 consecutive sections were manually tracked with ImageJ MtrackJ plugin. Comet count and comet tracks count were obtained using an ImageJ custom-written macro .

HDAC6 activity measurement.

HDAC6 activity was assessed using the Fluorogenic HDAC6 assay kit (Bioscience, \#50076) according to the manufacturer's instructions.

Soluble and polymerized tubulin fractionation

Soluble and polymerized tubulin was fractionated as described (Larrieu et al., 2014). Briefly, osteoclasts pre-treated or not with $10 \mu \mathrm{M}$ nocodazole for $2 \mathrm{~h}$ were lysed in Microtubules Stabilization Buffer (MSB: 85 mM PIPES pH 6.9, 1 mM EGTA, 1 mM $\mathrm{MgCl}_{2}, 2 \mathrm{M}$ glycerol, $0.5 \%$ triton, $4 \mu \mathrm{g} / \mathrm{ml}$ taxol) supplemented with proteases inhibitors. Lysates were kept in ice for $2 \mathrm{~min}$ and then centrifuged for $10 \mathrm{~min}$ at 13000 rpm. Laemmli buffer was added to the supernatants (soluble fraction). Pellets (polymerized fraction of proteins) were washed once in MSB without triton and resuspended in Laemmli buffer.

\section{Western Blot}

Whole osteoclast extracts were made in Laemmli buffer, resolved on SDS-PAGE and electrotransferred on nitrocellulose membranes. Immunoblotting was performed 
using the following primary antibodies: mouse anti-lys40 acetylated alpha tubulin (1/1000, Sigma, \#T6793), mouse anti-alpha tubulin (1/1000, Sigma, \#T6074), rabbit anti-GAPDH (1/2000, Cell Signaling, \#2118), rabbit anti-EB1 (1/2500, Sigma, \#E3406), rabbit anti-ser9 phospho GSK3 $\beta$ (1/1000, Cell Signaling, \#9322), rabbit anti-GSK3 $\beta$ (1/1000, Cell Signaling, \#12456), rabbit anti-ser473 phospho Akt (1/1000, Cell Signaling, \#4060), rabbit anti-Akt (1/1000, Cell Signaling, \#9272), rabbit anti-ser16 phospho Op18 (1/500, Santa Cruz, \#sc-12948-R), rabbit anti-Dock5 (1/2000, homemade) and rabbit anti-histone H3 (1/5000, Abcam, \#1791). Signals were visualized by the ECL Western Lightning Plus detection system (Perkin Elmer) with horseradish peroxidase-conjugated secondary antibodies (GE Healthcare) and quantified using ImageJ.

\section{Immunofluorescence and microscopy}

Osteoclasts differentiated on $13 \mathrm{~mm}$-diameter glass coverslips were fixed for $20 \mathrm{~min}$, in $10 \mu \mathrm{M}$ Taxol (Sigma, \#T7402) and 3,2\% paraformaldehyde in PHEM (60 mM Pipes, 25 $\mathrm{mM}$ Hepes, $10 \mathrm{mM}$ EGTA, $4 \mathrm{mM} \mathrm{MgSO}_{4}, \mathrm{pH}$ 6.9). After permeabilization with $0.1 \%$ Triton X100 for $1 \mathrm{~min}$ and blocking with 1\% BSA in PBS for $15 \mathrm{~min}$, osteoclasts were incubated for $1 \mathrm{~h}$ with Alexa Fluor 647-labelled phalloidin (1/1000, Life Technologies, \#A22287), mouse anti-lys40 acetylated alpha tubulin (1/500, Sigma, \#T6793), rat anti-alpha tubulin (1/200, Santa Cruz, \#sc-53030) or rabbit anti-Dock5 (1/100, homemade) and revealed with the adapted Alexa Fluor 488 or 546-conjugated secondary antibodies (1/1000, Life Technologies). Preparations were mounted in Citifluor mouting medium (Biovalley) and imaged with Leica SP5-SMD confocal microscope using 40X HCX Plan Apo CS oil 1.3NA or 63X HCX Plan Apo CS oil 1.4NA objectives. All imaging was performed at the Montpellier RIO Imaging facility (http://www.mri.cnrs.fr/en/). Immunofluorescent signals integrated density was quantified using ImageJ.

\section{Statistical analysis}

Graphs are represented as the mean \pm sem. Statistical significance was assessed with the nonparametric statistical tests mentioned in figure legends using GraphPad Prism (GraphPad Software, Inc). 


\section{Figure legends}

\section{Figure 1: Microtubule acetylation in Dock5 $5^{-/-}$osteoclasts}

(A) Representative western blot showing acetylated tubulin, total tubulin and GAPDH in Dock5 ${ }^{+/+}$and Dock5 ${ }^{-/-}$osteoclasts (left). Acetylated tubulin levels from 7 independent experiments were normalized to total tubulin and represented on a bar graph (right). *, p<0.05 using one-tailed Mann Whitney test. (B) Actin (blue), acetylated (green) and total (red) tubulin immunofluorescence staining of Dock $5^{+/+}$ and Dock $5^{-/-}$osteoclasts. For each genotype, bottom panels show an enlarged view of the top panels boxed areas. Scale bar= $20 \mu \mathrm{m}$. (C) Graph showing acetylated tubulin integrated density from immunofluorescent staining of 13-14 Dock $5^{+/+}$and Dock $5^{-/}$osteoclasts from different experiments. ${ }^{* *}, p<0.01$ as determined by twotailed Mann Whitney test.

\section{Figure 2: Microtubule dynamic instability in Dock $5^{-/-}$osteoclasts}

(B) GFP-positive comets were tracked in Dock5 ${ }^{+/+}$and Dock5 ${ }^{-/-}$osteoclasts infected with EB3-GFP. Scale bar= $20 \mu \mathrm{m}$. Bar graphs showing microtubule growth (B) duration, (C) distance and (D) speed as well as (E) comets number $/ \mu \mathrm{m}^{2}$ and (F) comet tracks number / $\mathrm{mm}^{3} / \mathrm{min}$ of 18-19 osteoclasts from 4 independent experiments. (B-F) ns, not significant; ${ }^{*}, p<0.05$; ${ }^{* * *} p<0.0001$; ${ }^{* * * *} p<0.00001$ as determined by two-tailed Mann Whitney test.

\section{Figure 3: C21 effect on microtubule acetylation and dynamic instability}

(A) Representative western blot showing acetylated tubulin, total tubulin and GAPDH in wild-type osteoclasts treated (C21) or not (vehicle) with $100 \mu \mathrm{M} \mathrm{C} 21$ for 1 hour (left). Acetylated tubulin levels from 6 independent experiments were normalized to total tubulin and represented on a bar graph (right). (B) Actin (blue), acetylated (green) and total (red) tubulin immunofluorescence staining of Dock $5^{+/+}$osteoclasts treated (+C21) or not (-C21) with $100 \mu \mathrm{M} \mathrm{C} 21$ for 1 hour. For each condition, bottom panels show an enlarged view of the top panels boxed areas. Scale bar= $20 \mu \mathrm{m}$. (C) Bar graphs showing microtubule growth duration, distance and speed in Dock $5^{+/+}$ osteoclasts expressing EB3-GFP and treated (C21) or not (vehicle) in the same conditions as above in 14-20 osteoclasts from 3 independent experiments. (A,C) *, 
$\mathrm{p}<0.05 ;{ }^{* * *}, \mathrm{p}<0.0001 ;{ }^{* * *}, \mathrm{p}<0.00001$ as determined by two-tailed Mann-Whitney test.

Figure 4: Rac inhibitor EHT1864 effect on microtubule acetylation

(A) Representative western blot showing acetylated tubulin, total tubulin and GAPDH in wild-type osteoclasts treated with increasing concentrations of EHT1864 for 2 hours (left). Acetylated tubulin mean level from 3 independent experiments \pm sem were normalized to total tubulin and represented on a bar graph (right). (B) Actin (blue), acetylated (green) and total (red) tubulin immunofluorescence staining of Dock5 ${ }^{+/+}$osteoclasts treated (EHT1864) or not (vehicle) with $10 \mu \mathrm{M}$ EHT1864 for 2 hours. Scale bar $=20 \mu \mathrm{m}$.

Figure 5: Defective signaling pathways in Dock5 ${ }^{-/-}$osteoclasts

(A) Western blot showing Dock5 association to soluble (S) or polymerized (P) tubulin from wild-type osteoclasts treated (+) or not (-) with $10 \mu \mathrm{M}$ nocodazole for 1 hour. (B) HDAC6 activity in Dock $5^{+/+}$and Dock5 ${ }^{-/-}$osteoclasts. ns, not significant as determined by Wilcoxon Signed Rank test. Representative western blots showing (C) GSK3 $\beta$ and (D) Akt phosphorylation levels in Dock $5^{+/+}$and Dock $5^{-/-}$osteoclasts (left). Signals from 3-5 independent experiments were normalized to the total protein levels (right). ns, not significant; ${ }^{*}, p<0.05$ as determined by two-tailed Mann-Whitney test. (E) $\mathrm{Dock}^{+/+}$and Dock5 $5^{-/-}$osteoclasts were treated $(\mathrm{LiCl})$ or not (-) with $20 \mathrm{mM}$ lithium chloride for 5 hours and tubulin acetylation was observed by western blot (left). The treatment effect on actin belt formation/stabilization was quantified from 3 independent experiments (right). ns, not significant as determined by two-tailed Mann Whitney test.

\section{Figure 6: Proposed role of Dock5 in osteoclast adhesion structure establishment}

(A) $\alpha \beta$ integrin activation induces Doc5 recruitment to the Src/Pyk2/p130Cas complex leading to Rac1 activation and podosome assembly and patterning. In addition, Dock5 binding to Akt brings the latter sufficiently close to GSK3 $\beta$ to inactivate it by phosphorylation on serine 9. EB1 can interact with unidentified (?) protein(s) associated to podosomes allowing the acetylated microtubules to stabilize 
the actin structure. (B) In the absence of Dock5, decreased Rac1 activation prevents efficient podosome formation. More, activated GSK3 $\beta$ phosphorylates unidentified (?) protein(s) hindering its / their interaction with EB1-decorated microtubules that are destabilized.

\section{Supplementary figure 1: EB3-GFP comets in Dock5 $5^{+/+}$and Dock $5^{-/-}$osteoclasts}

Representatives movies with 1 frame per second showing EB3-GFP comets from (A) Dock5 $^{+/+}$and (B) Dock5 ${ }^{-/-}$osteoclasts.

\section{Supplementary figure 2: EB3-GFP comets analysis in C21-treated wild-type osteoclasts}

Bar graphs showing (A) comets number $/ \mu \mathrm{m}^{2}$ and (B) comet tracks number $/ \mu \mathrm{m}^{3} /$ min in wild-type osteoclasts treated (C21) or not (vehicle) with $100 \mu \mathrm{M} \mathrm{C} 21$ for 1 hour in 3 independent experiments. ns, not significant as determined by two-tailed MannWhitney test.

\section{Funding}

This study was supported by the French Centre National de la Recherche Scientifique (CNRS), Montpellier University and grants from the French Fondation pour la Recherche Médicale (Grant \# LEQ20151134530) and from the GEFLUC Languedoc Roussillon (grant \#A.P. 2015) to A.B. and a grant from the Fondation ARC 2015 (grant \# PJA 20151203109) to V.V..

\section{Acknowledgments}

We acknowledge the Montpellier RIO Imaging (https://www.mri.cnrs.fr/en/) and the RAM (http://www.ram.cnrs.fr/) facilities. We thank J. Boudeau (CRBM, Montpellier, France) for EB3-GFP expressing vector, Carlos Sanchez-Huertas (CRBM, Montpellier, France) for helpful discussions and Anne Morel (CRBM, Montpellier, France) for the management of Dock5 transgenic mice colonies.

\section{Conflict of interest statement}

The authors have declared no conflict of interest. 


\section{References}

Akhmanova, A., and Steinmetz, M.O. (2015). Control of microtubule organization and dynamics: two ends in the limelight. Nat. Rev. Mol. Cell Biol. 16, 711-726.

Akisaka, T., Yoshida, H., and Takigawa, T. (2011). Differential distribution of posttranslationally modified microtubules in osteoclasts. J. Histochem. Cytochem. 59, 630-638.

Asada, N., and Sanada, K. (2010). LKB1-mediated spatial control of GSK3beta and adenomatous polyposis coli contributes to centrosomal forward movement and neuronal migration in the developing neocortex. J. Neurosci. 30, 8852-8865.

Bacon, T., Seiler, C., Wolny, M., Hughes, R., Watson, P., Schwabe, J., Grigg, R., and Peckham, M. (2015). Histone deacetylase 3 indirectly modulates tubulin acetylation. Biochemical Journal 472, 367-377.

Barnat, M., Benassy, M.-N., Vincensini, L., Soares, S., Fassier, C., Propst, F., Andrieux, A., von Boxberg, Y., and Nothias, F. (2016). The GSK3-MAP1B pathway controls neurite branching and microtubule dynamics. Mol. Cell. Neurosci. 72, 9-21.

Batsir, S., Geiger, B., and Kam, Z. (2017). Dynamics of the sealing zone in cultured osteoclasts. Cytoskeleton (Hoboken) 74, 72-81.

Biosse Duplan, M., Zalli, D., Stephens, S., Zenger, S., Neff, L., Oelkers, J.M., Lai, F.P.L., Horne, W., Rottner, K., and Baron, R. (2014). Microtubule dynamic instability controls podosome patterning in osteoclasts through EB1, cortactin, and Src. Mol. Cell. Biol. 34, 16-29.

Biswas, M., Chatterjee, S.S., Boila, L.D., Chakraborty, S., Banerjee, D., and Sengupta, A. (2019). MBD3/NuRD loss participates with KDM6A program to promote DOCK5/8 expression and Rac GTPase activation in human acute myeloid leukemia. FASEB J. fj201801035R.

Calle, Y., Jones, G.E., Jagger, C., Fuller, K., Blundell, M.P., Chow, J., Chambers, T., and Thrasher, A.J. (2004). WASp deficiency in mice results in failure to form osteoclast sealing zones and defects in bone resorption. Blood 103, 3552-3561.

Cappariello, A., Maurizi, A., Veeriah, V., and Teti, A. (2014). The Great Beauty of the osteoclast. Archives of Biochemistry and Biophysics 558, 70-78.

Chellaiah, M.A., Soga, N., Swanson, S., McAllister, S., Alvarez, U., Wang, D., Dowdy, S.F., and Hruska, K.A. (2000). Rho-A Is Critical for Osteoclast Podosome Organization, Motility, and Bone Resorption. J. Biol. Chem. 275, 11993-12002.

Croke, M., Ross, F.P., Korhonen, M., Williams, D.A., Zou, W., and Teitelbaum, S.L. (2011). Rac deletion in osteoclasts causes severe osteopetrosis. J. Cell. Sci. 124, 3811-3821.

Destaing, O., Saltel, F., Géminard, J.-C., Jurdic, P., and Bard, F. (2003). Podosomes display actin turnover and dynamic self-organization in osteoclasts expressing actingreen fluorescent protein. Mol. Biol. Cell 14, 407-416. 
Destaing, O., Saltel, F., Gilquin, B., Chabadel, A., Khochbin, S., Ory, S., and Jurdic, P. (2005). A novel Rho-mDia2-HDAC6 pathway controls podosome patterning through microtubule acetylation in osteoclasts. J. Cell. Sci. 118, 2901-2911.

Destaing, O., Sanjay, A., Itzstein, C., Horne, W.C., Toomre, D., De Camilli, P., and Baron, R. (2008). The Tyrosine Kinase Activity of c-Src Regulates Actin Dynamics and Organization of Podosomes in Osteoclasts. Mol Biol Cell 19, 394-404.

Faccio, R., Teitelbaum, S.L., Fujikawa, K., Chappel, J., Zallone, A., Tybulewicz, V.L., Ross, F.P., and Swat, W. (2005). Vav3 regulates osteoclast function and bone mass. Nat. Med. 11, 284-290.

Ferrandez, Y., Zhang, W., Peurois, F., Akendengué, L., Blangy, A., Zeghouf, M., and Cherfils, J. (2017). Allosteric inhibition of the guanine nucleotide exchange factor DOCK5 by a small molecule. Sci Rep 7, 14409.

Frank, S.R., Köllmann, C.P., van Lidth de Jeude, J.F., Thiagarajah, J.R., Engelholm, L.H., Frödin, M., and Hansen, S.H. (2017). The focal adhesion-associated proteins DOCK5 and GIT2 comprise a rheostat in control of epithelial invasion. Oncogene 36, 1816-1828.

Garza, J.C., Qi, X., Gjeluci, K., Leussis, M.P., Basu, H., Reis, S.A., Zhao, W.N., Piguel, N.H., Penzes, P., Haggarty, S.J., et al. (2018). Disruption of the psychiatric risk gene Ankyrin 3 enhances microtubule dynamics through GSK3/CRMP2 signaling. Transl Psychiatry 8, 135.

Gąssowska, M., Czapski, G.A., Pajak, B., Cieślik, M., Lenkiewicz, A.M., and Adamczyk, A. (2014). Extracellular a-synuclein leads to microtubule destabilization via GSK-3ß-dependent Tau phosphorylation in PC12 cells. PLoS ONE 9, e94259.

Gil-Henn, H., Destaing, O., Sims, N.A., Aoki, K., Alles, N., Neff, L., Sanjay, A., Bruzzaniti, A., De Camilli, P., Baron, R., et al. (2007). Defective microtubuledependent podosome organization in osteoclasts leads to increased bone density in Pyk2(-/-) mice. J. Cell Biol. 178, 1053-1064.

Janke, C., and Montagnac, G. (2017). Causes and Consequences of Microtubule Acetylation. Current Biology 27, R1287-R1292.

Kumar, P., Lyle, K.S., Gierke, S., Matov, A., Danuser, G., and Wittmann, T. (2009). GSK3beta phosphorylation modulates CLASP-microtubule association and lamella microtubule attachment. J. Cell Biol. 184, 895-908.

Larrieu, D., Britton, S., Demir, M., Rodriguez, R., and Jackson, S.P. (2014). Chemical inhibition of NAT10 corrects defects of laminopathic cells. Science 344, 527-532.

Laurin, M., and Côté, J.-F. (2014). Insights into the biological functions of Dock family guanine nucleotide exchange factors. Genes Dev. 28, 533-547.

Liz, M.A., Mar, F.M., Santos, T.E., Pimentel, H.I., Marques, A.M., Morgado, M.M., Vieira, S., Sousa, V.F., Pemble, H., Wittmann, T., et al. (2014). Neuronal deletion of GSK3 $\beta$ increases microtubule speed in the growth cone and enhances axon 
regeneration via CRMP-2 and independently of MAP1B and CLASP2. BMC Biol. 12, 47.

Lowe, C., Yoneda, T., Boyce, B.F., Chen, H., Mundy, G.R., and Soriano, P. (1993). Osteopetrosis in Src-deficient mice is due to an autonomous defect of osteoclasts. Proc. Natl. Acad. Sci. U.S.A. 90, 4485-4489.

Magalhaes, J.K.R.S., Grynpas, M.D., Willett, T.L., and Glogauer, M. (2011). Deleting Rac1 improves vertebral bone quality and resistance to fracture in a murine ovariectomy model. Osteoporos Int 22, 1481-1492.

Matsumoto, T., Nagase, Y., Hirose, J., Tokuyama, N., Yasui, T., Kadono, Y., Ueki, K., Kadowaki, T., Nakamura, K., and Tanaka, S. (2013). Regulation of bone resorption and sealing zone formation in osteoclasts occurs through protein kinase B-mediated microtubule stabilization. J. Bone Miner. Res. 28, 1191-1202.

McMichael, B.K., Cheney, R.E., and Lee, B.S. (2010). Myosin X regulates sealing zone patterning in osteoclasts through linkage of podosomes and microtubules. J. Biol. Chem. 285, 9506-9515.

Nagai, Y., Osawa, K., Fukushima, H., Tamura, Y., Aoki, K., Ohya, K., Yasuda, H., Hikiji, H., Takahashi, M., Seta, Y., et al. (2013). p130Cas, Crk-associated substrate, plays important roles in osteoclastic bone resorption. J. Bone Miner. Res. 28, 24492462.

Namekata, K., Harada, C., Guo, X., Kimura, A., Kittaka, D., Watanabe, H., and Harada, T. (2012). Dock3 Stimulates Axonal Outgrowth via GSK-3ß-Mediated Microtubule Assembly. J. Neurosci. 32, 264-274.

Ogawa, K., Tanaka, Y., Uruno, T., Duan, X., Harada, Y., Sanematsu, F., Yamamura, K., Terasawa, M., Nishikimi, A., Côté, J.-F., et al. (2014). DOCK5 functions as a key signaling adaptor that links FceRl signals to microtubule dynamics during mast cell degranulation. J. Exp. Med. 211, 1407-1419.

Omi, N., Kiyokawa, E., Matsuda, M., Kinoshita, K., Yamada, S., Yamada, K., Matsushima, Y., Wang, Y., Kawai, J., Suzuki, M., et al. (2008). Mutation of Dock5, a member of the guanine exchange factor Dock180 superfamily, in the rupture of lens cataract mouse. Exp. Eye Res. 86, 828-834.

Purev, E., Neff, L., Horne, W.C., and Baron, R. (2009). c-Cbl and Cbl-b act redundantly to protect osteoclasts from apoptosis and to displace HDAC6 from betatubulin, stabilizing microtubules and podosomes. Mol. Biol. Cell 20, 4021-4030.

Qu, X., Yuan, F.N., Corona, C., Pasini, S., Pero, M.E., Gundersen, G.G., Shelanski, M.L., and Bartolini, F. (2017). Stabilization of dynamic microtubules by mDia1 drives Tau-dependent Aß1-42 synaptotoxicity. J. Cell Biol. 216, 3161-3178.

Sánchez-Huertas, C., Freixo, F., Viais, R., Lacasa, C., Soriano, E., and Lüders, J. (2016). Non-centrosomal nucleation mediated by augmin organizes microtubules in post-mitotic neurons and controls axonal microtubule polarity. Nat Commun 7, 12187. 
Schmidt, N., Basu, S., Sladecek, S., Gatti, S., van Haren, J., Treves, S., Pielage, J., Galjart, N., and Brenner, H.R. (2012). Agrin regulates CLASP2-mediated capture of microtubules at the neuromuscular junction synaptic membrane. J. Cell Biol. 198, 421-437.

Shutes, A., Onesto, C., Picard, V., Leblond, B., Schweighoffer, F., and Der, C.J. (2007). Specificity and mechanism of action of EHT 1864, a novel small molecule inhibitor of Rac family small GTPases. J. Biol. Chem. 282, 35666-35678.

Takegahara, N., Kang, S., Nojima, S., Takamatsu, H., Okuno, T., Kikutani, H., Toyofuku, T., and Kumanogoh, A. (2010). Integral roles of a guanine nucleotide exchange factor, FARP2, in osteoclast podosome rearrangements. FASEB J. 24, 4782-4792.

Touaitahuata, H., Blangy, A., and Vives, V. (2014). Modulation of osteoclast differentiation and bone resorption by Rho GTPases. Small GTPases 5.

Vives, V., Laurin, M., Cres, G., Larrousse, P., Morichaud, Z., Noel, D., Côté, J.-F., and Blangy, A. (2011). The Rac1 exchange factor Dock5 is essential for bone resorption by osteoclasts. J. Bone Miner. Res. 26, 1099-1110.

Vives, V., Cres, G., Richard, C., Busson, M., Ferrandez, Y., Planson, A.-G., Zeghouf, M., Cherfils, J., Malaval, L., and Blangy, A. (2015). Pharmacological inhibition of Dock5 prevents osteolysis by affecting osteoclast podosome organization while preserving bone formation. Nat Commun 6, 6218.

Watabe-Uchida, M., John, K.A., Janas, J.A., Newey, S.E., and Van Aelst, L. (2006). The Rac activator DOCK7 regulates neuronal polarity through local phosphorylation of stathmin/Op18. Neuron 51, 727-739.

Watanabe, M., Terasawa, M., Miyano, K., Yanagihara, T., Uruno, T., Sanematsu, F., Nishikimi, A., Côté, J.-F., Sumimoto, H., and Fukui, Y. (2014). DOCK2 and DOCK5 act additively in neutrophils to regulate chemotaxis, superoxide production, and extracellular trap formation. J. Immunol. 193, 5660-5667.

Wittmann, T., Bokoch, G.M., and Waterman-Storer, C.M. (2004). Regulation of microtubule destabilizing activity of Op18/stathmin downstream of Rac1. J. Biol. Chem. 279, 6196-6203.

Xu, W., Ge, Y., Liu, Z., and Gong, R. (2015). Glycogen synthase kinase $3 \beta$ orchestrates microtubule remodeling in compensatory glomerular adaptation to podocyte depletion. J. Biol. Chem. 290, 1348-1363.

Xu, X., Yoshizaki, H., Ishigaki, Y., Kubo, E., Minato, H., and Kiyokawa, E. (2017a). Upregulation of multiple signaling pathways by Dock5 deletion in epithelial cells. Mol. Vis. 23, 1081-1092.

Xu, Z., Schaedel, L., Portran, D., Aguilar, A., Gaillard, J., Marinkovich, M.P., Théry, M., and Nachury, M.V. (2017b). Microtubules acquire resistance from mechanical breakage through intralumenal acetylation. Science 356, 328-332. 
Yang, Y.-T., Wang, C.-L., and Van Aelst, L. (2012). DOCK7 interacts with TACC3 to regulate interkinetic nuclear migration and cortical neurogenesis. Nat. Neurosci. 15, 1201-1210.

Zhou, F.-Q., Zhou, J., Dedhar, S., Wu, Y.-H., and Snider, W.D. (2004). NGF-induced axon growth is mediated by localized inactivation of GSK-3beta and functions of the microtubule plus end binding protein APC. Neuron 42, 897-912.

Zilberman, Y., Ballestrem, C., Carramusa, L., Mazitschek, R., Khochbin, S., and Bershadsky, A. (2009). Regulation of microtubule dynamics by inhibition of the tubulin deacetylase HDAC6. Journal of Cell Science 122, 3531-3541. 
A

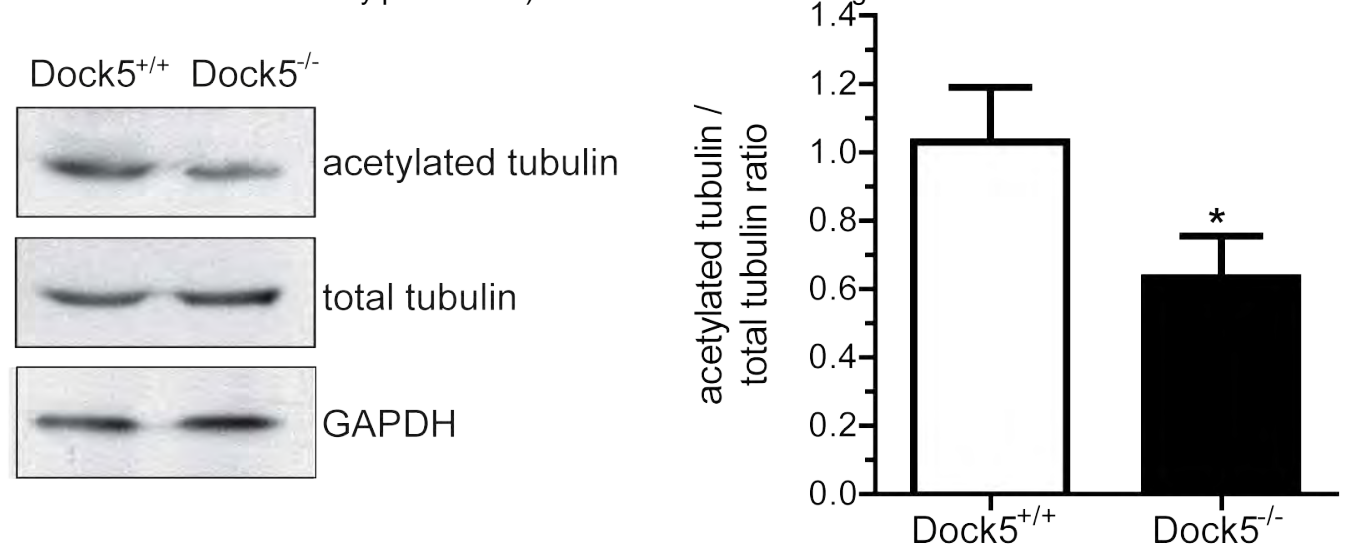

B
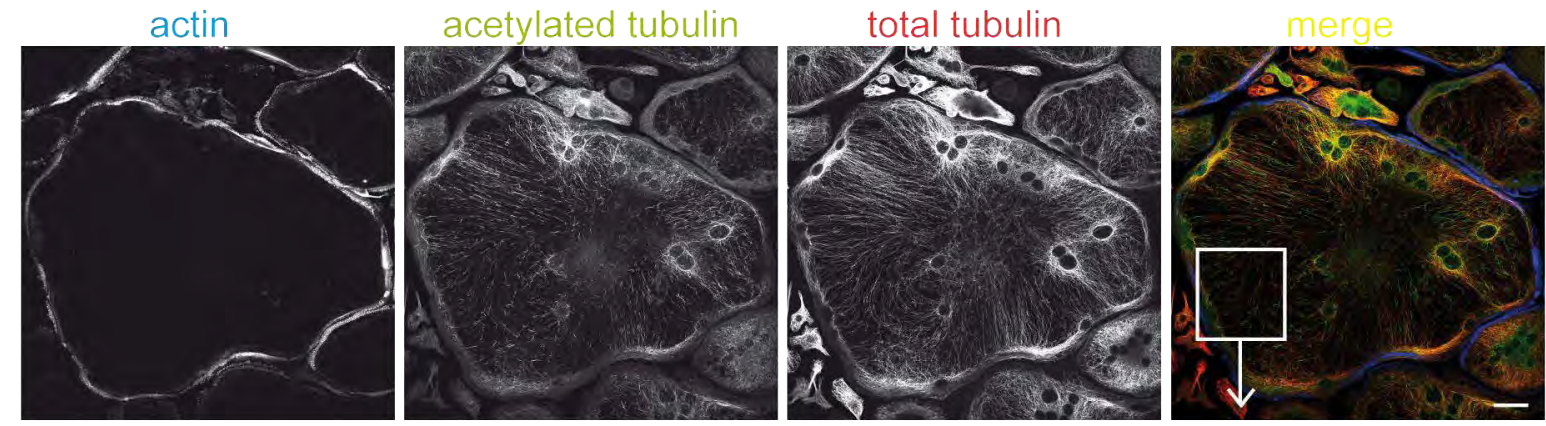

Dock5

+ ++

Dock5

-/-
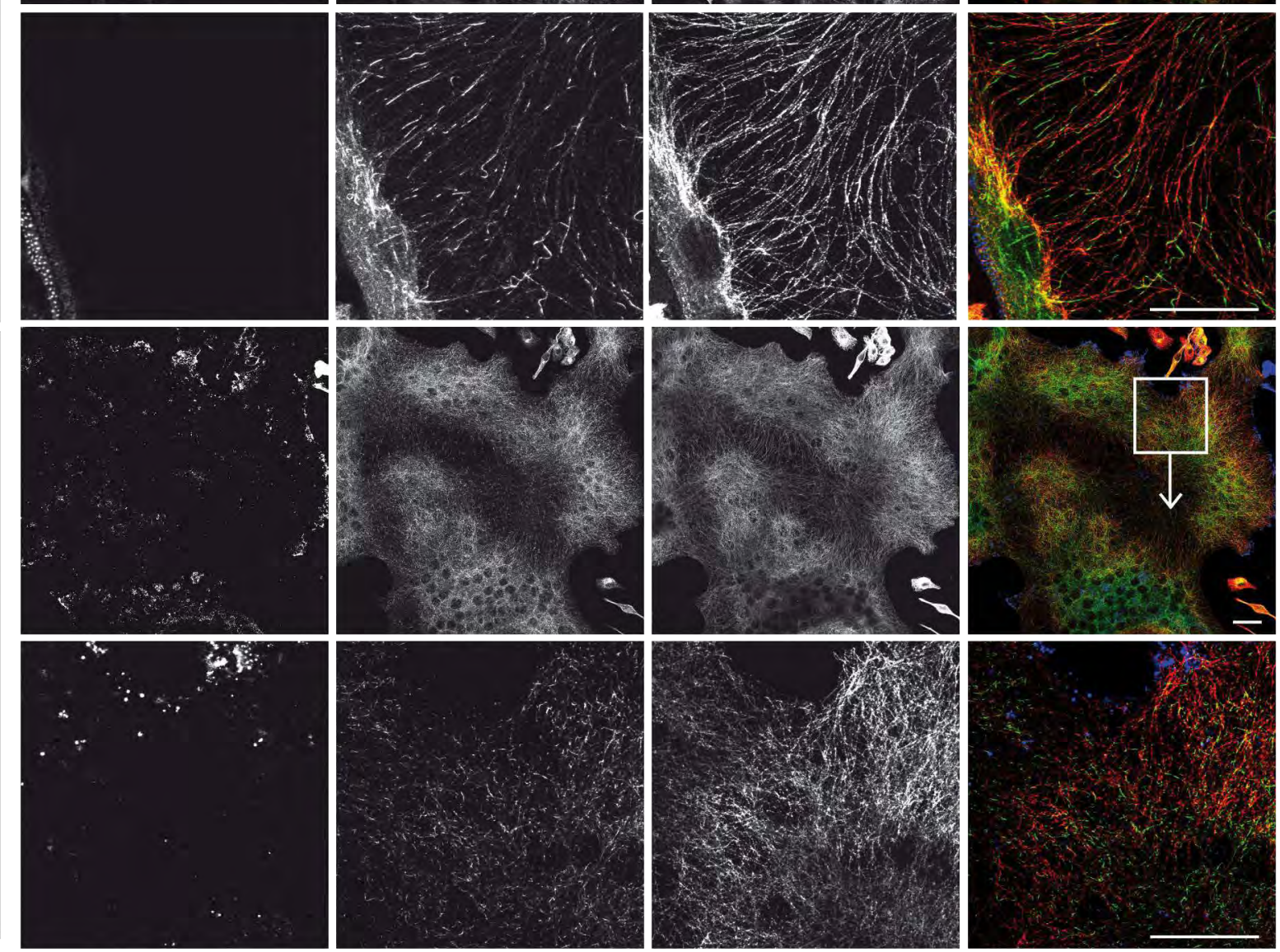

C

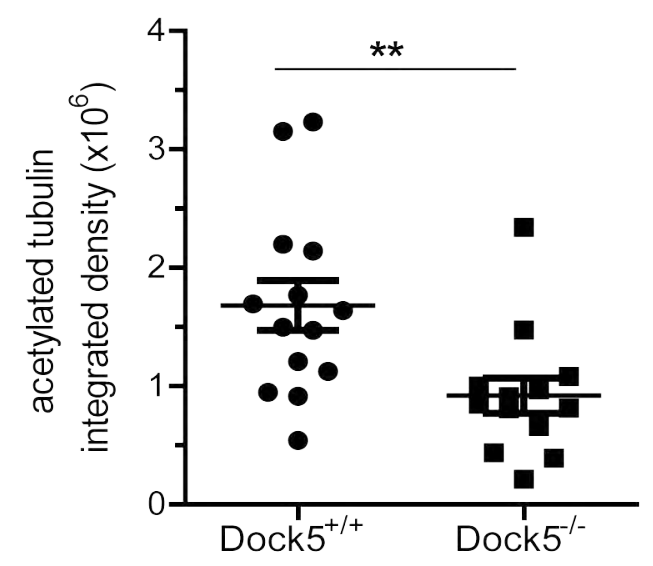


bioRxiv preprint doi: https://doi.org/10.1101/653055; this version posted June 4, 2019. The copyright holder for this preprint (which was not certified by peer review) is the author/funder. All rights reserved. No reuse allowed without permission.

A

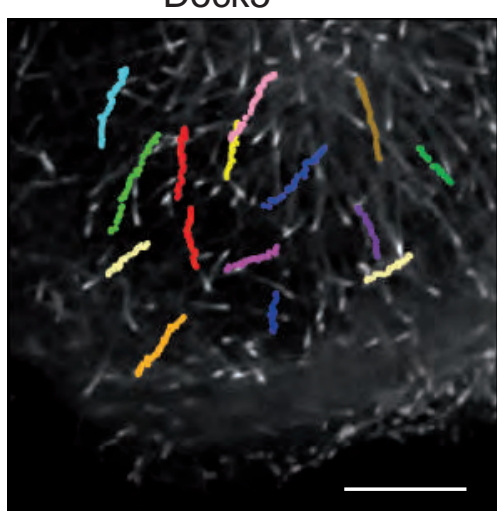

B

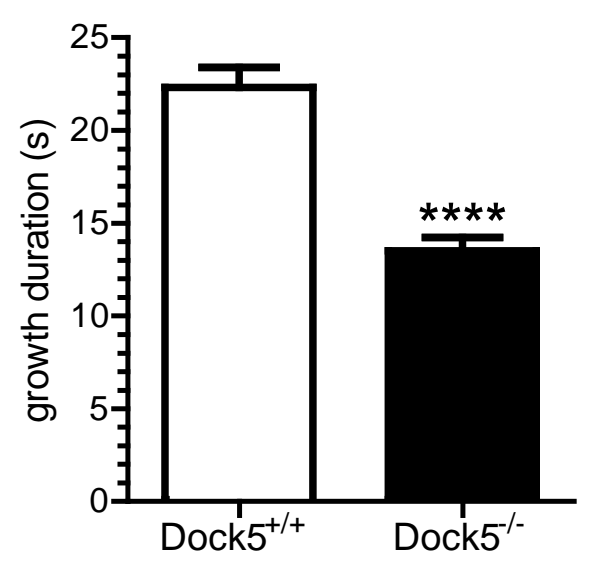

E

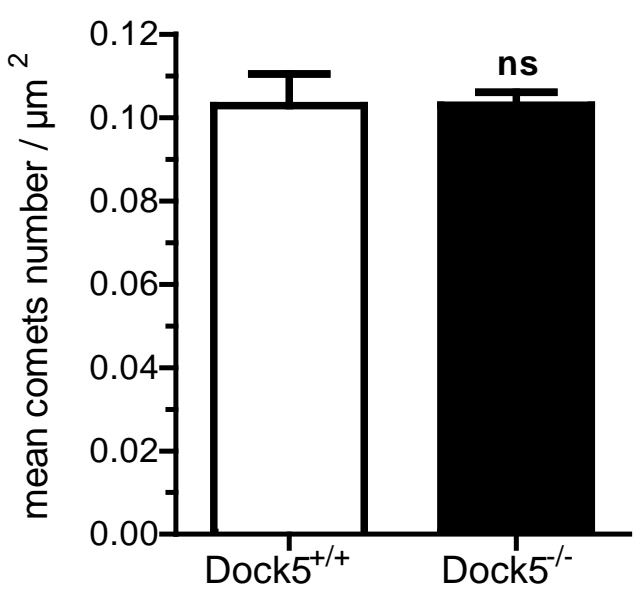
Dock5 $5^{-1-}$

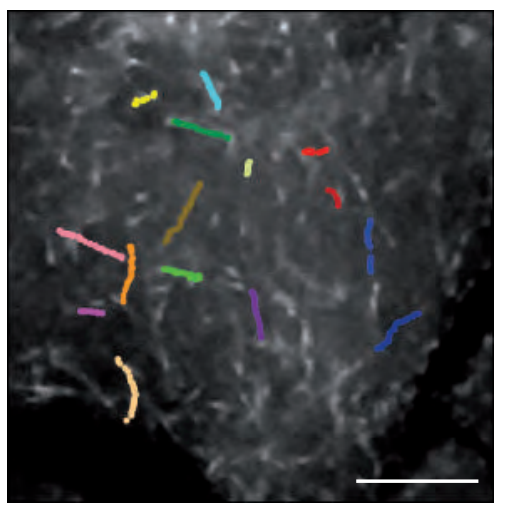

C

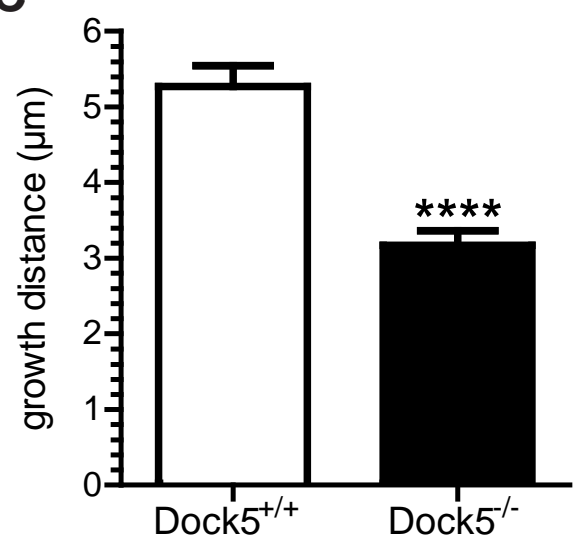

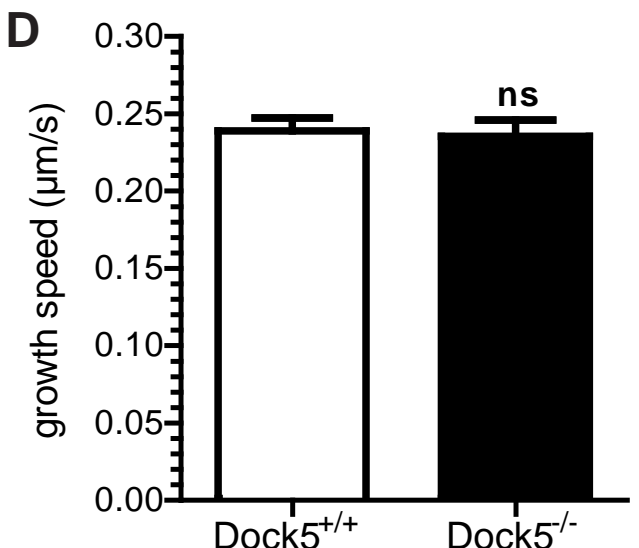

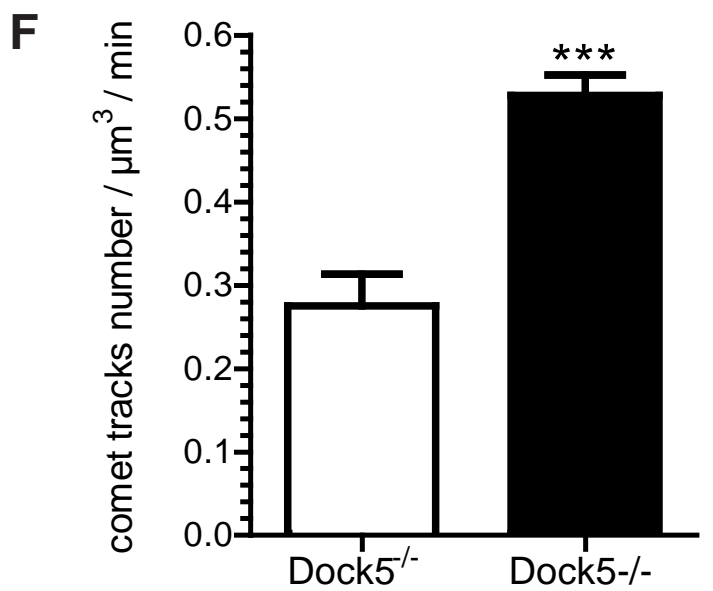


bioRxiv preprint doi: https://doi.org/10.1101/653055; this version posted June 4, 2019. The copyright holder for this preprint (which was

A not certified by peer review) is the author/funder 6 All rights reserved. No reuse allowed without permission.

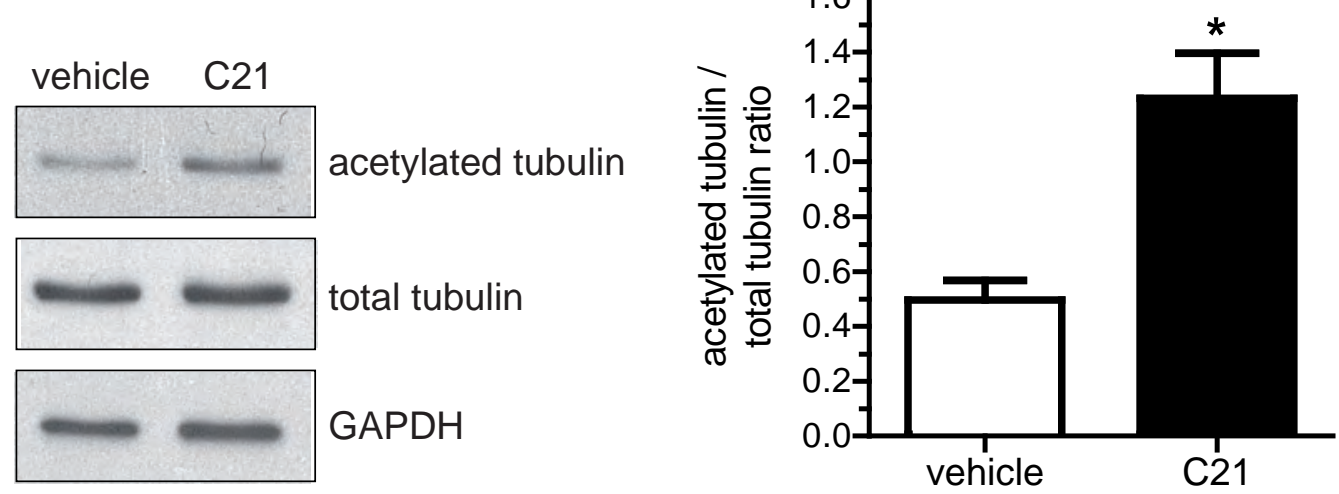

B

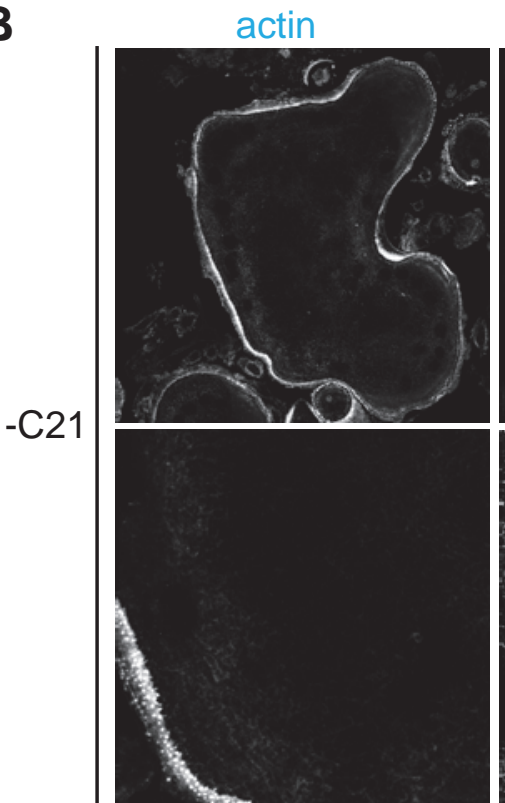

acetylated tubulin
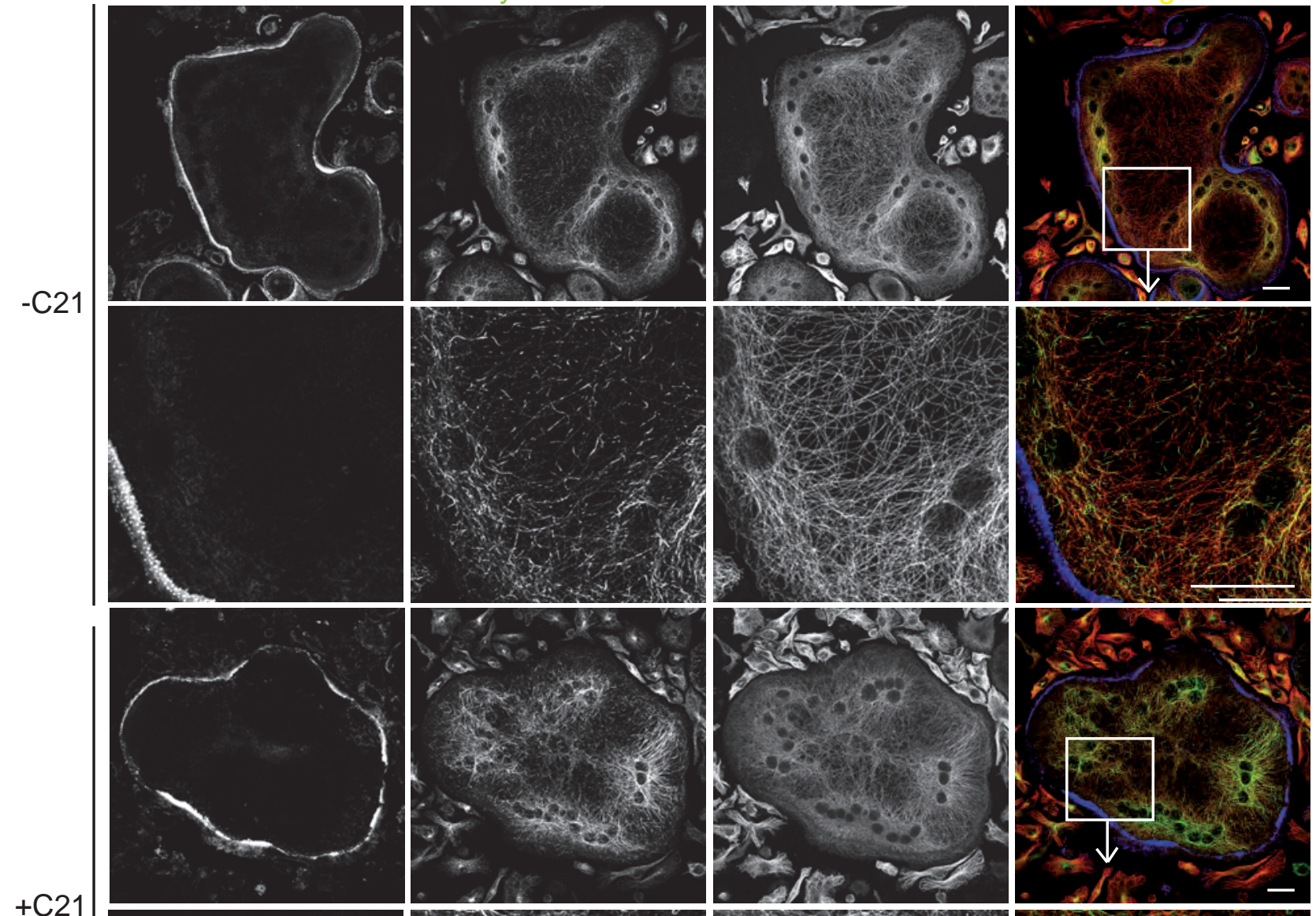

$+\mathrm{C} 21$
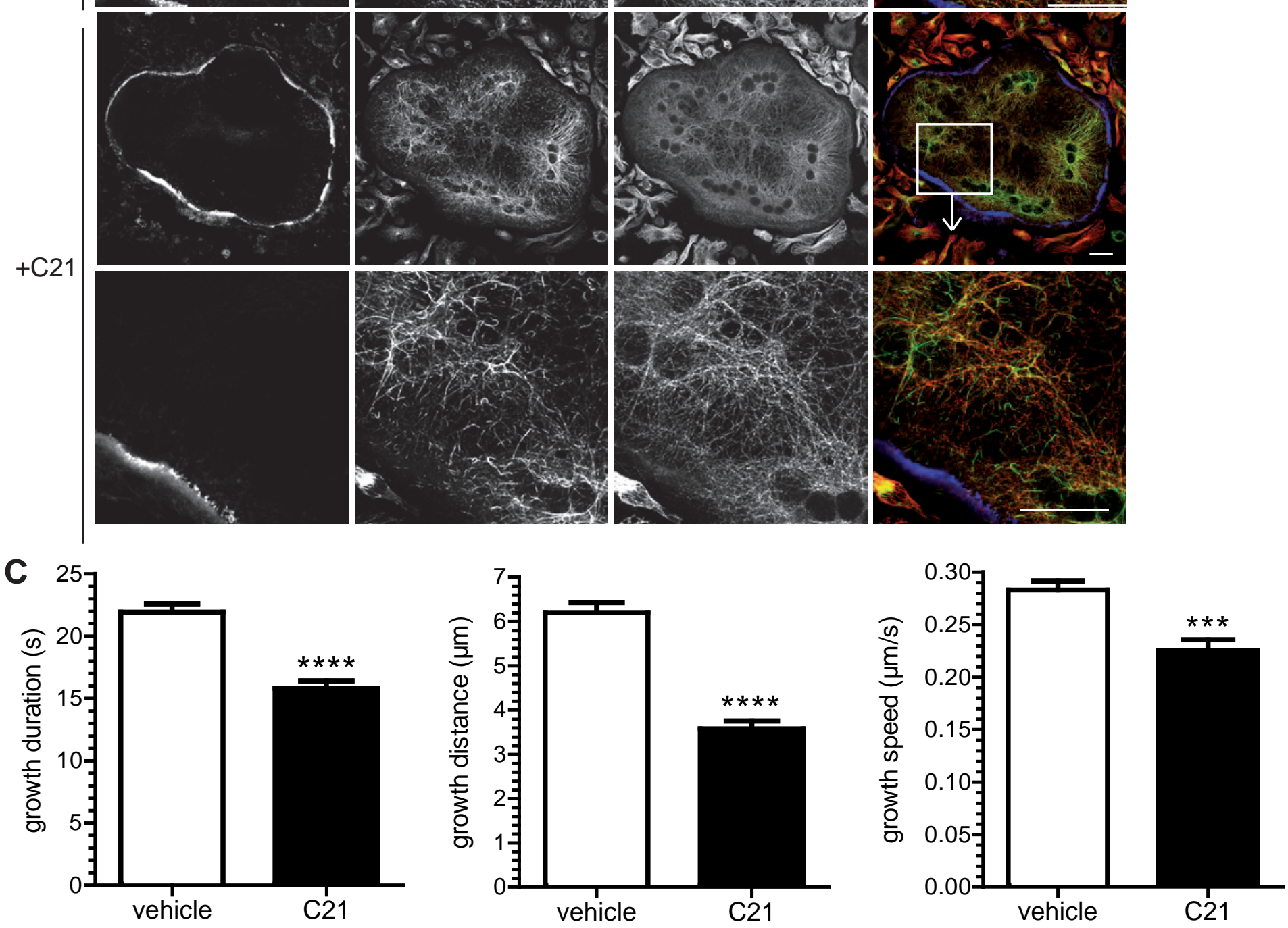

Figure 3 

A bioRxiv preprint doi: https://doi.org/10.1101/653055; this version posted June 4, 2019. The copyright holder for this preprint (which was
not certified by peer review) is the author/funder. All rights reserved. No reuse allowed without permission.

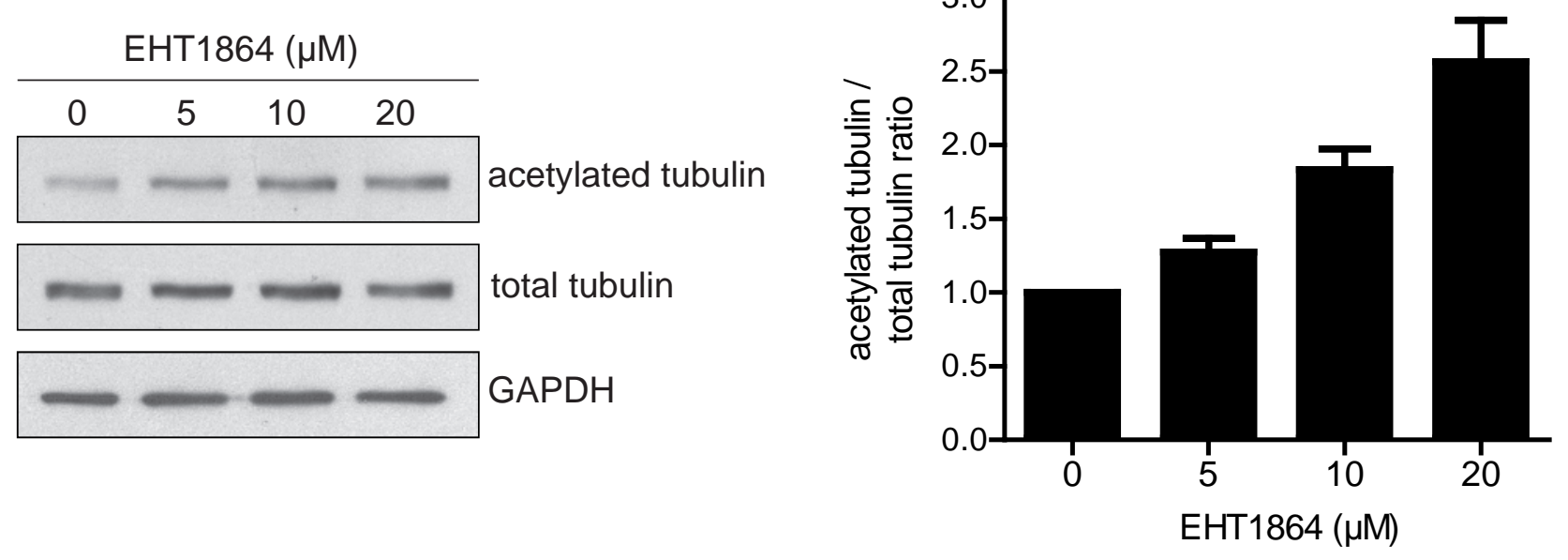

B

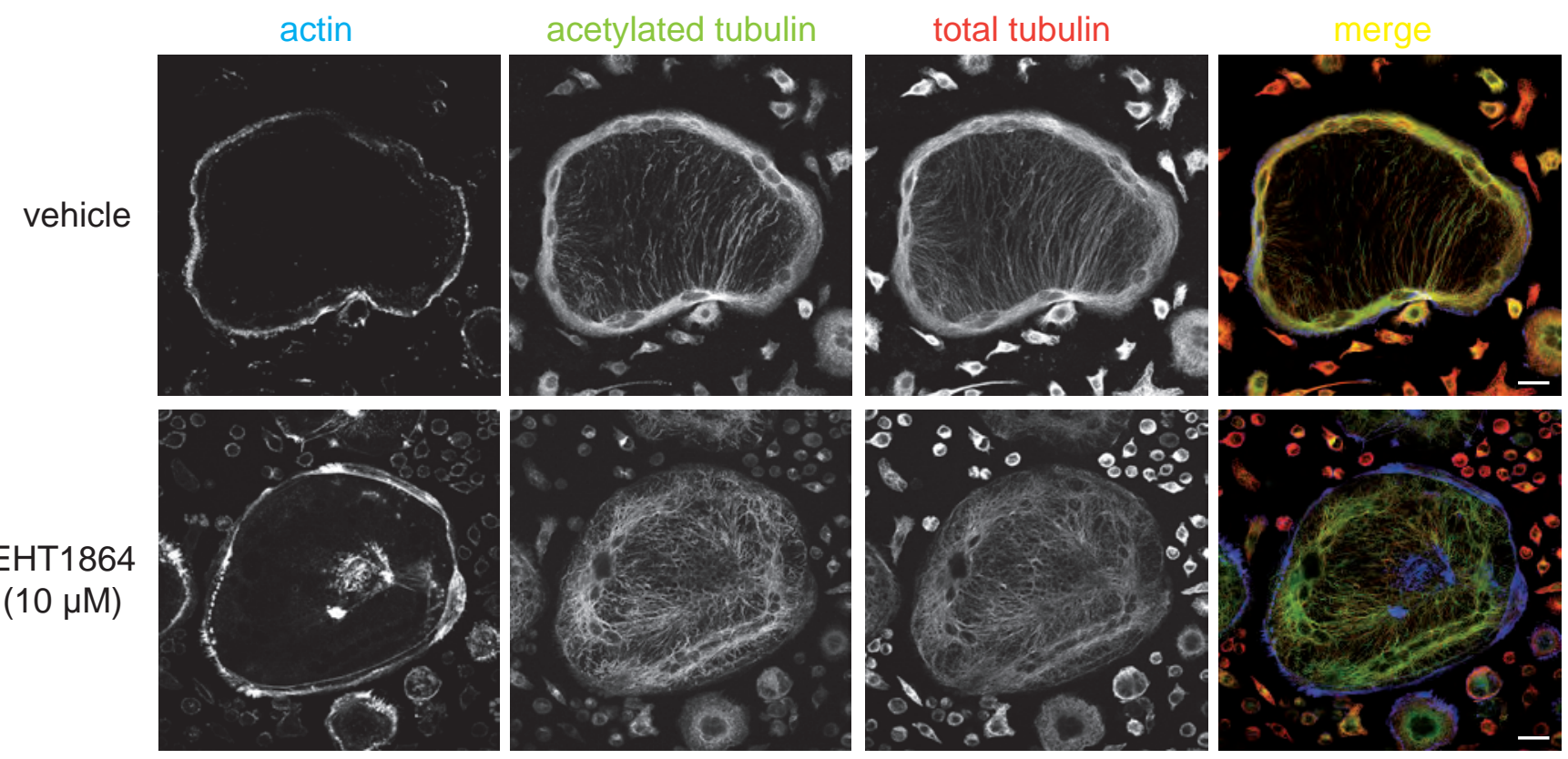


bioRxiv preprint doi: https://doi.org/10.1101/653055; this version posted June 4, 2019 The copyright holder for this preprint (which was

A nocodazole: not certified by peer revievt is the author/funder. All rights reserved. Nomuse allowed w.

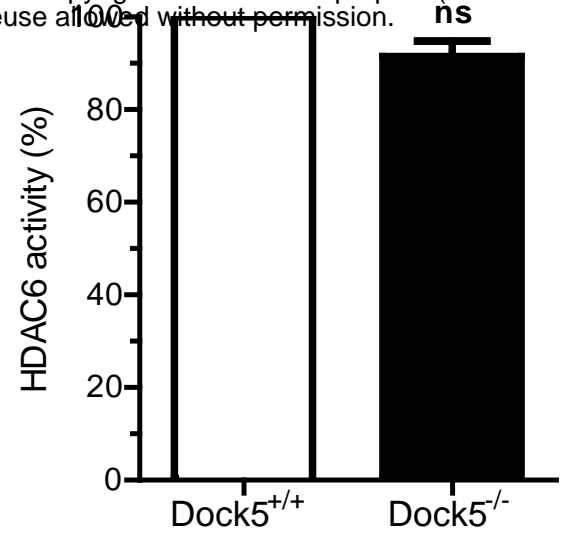

C

Dock5+/+ Dock5 ${ }^{-/}$
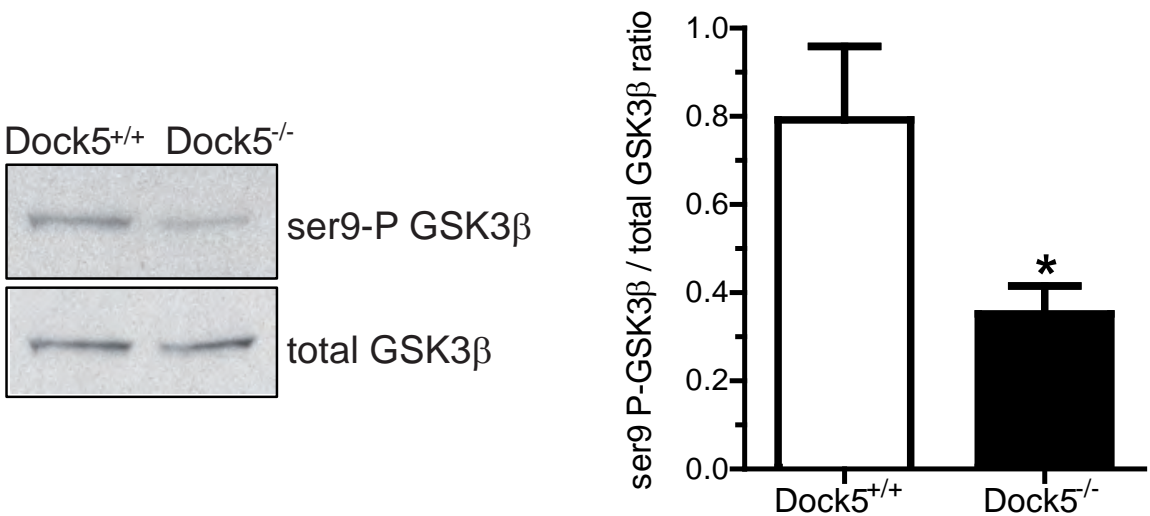

D

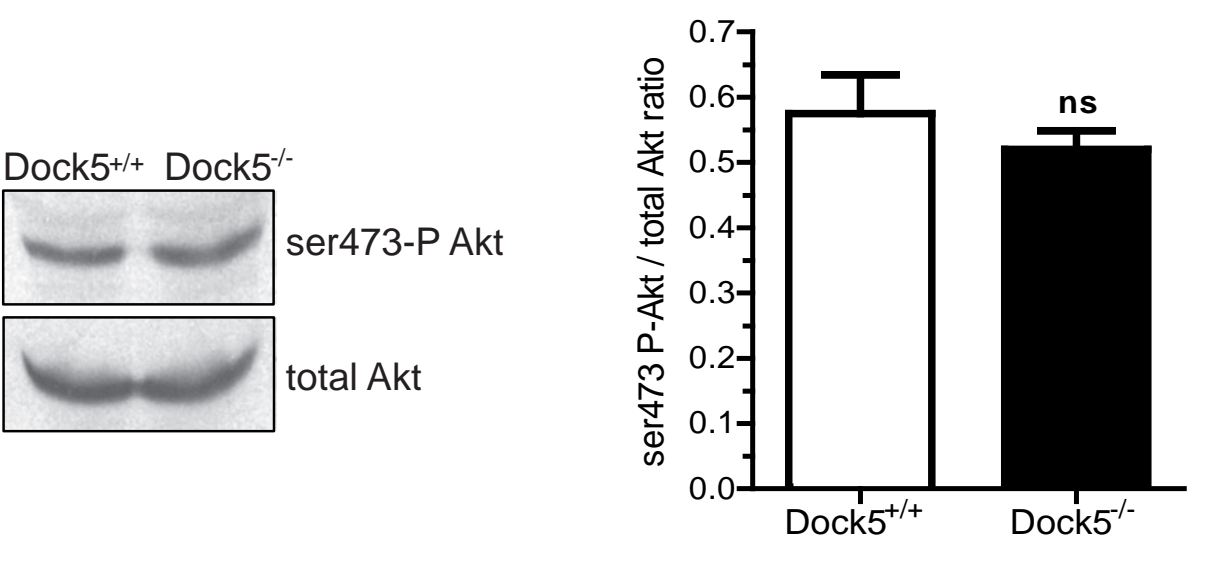

$\mathbf{E}$

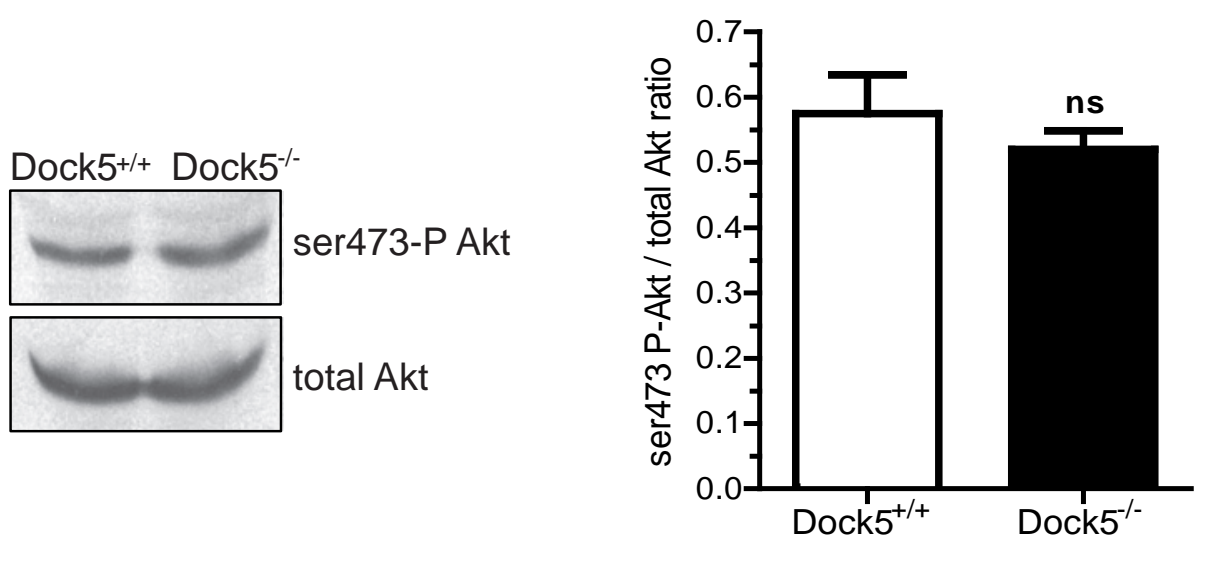

total tubulin acetylated tubulin GAPDH histone $\mathrm{H} 3$
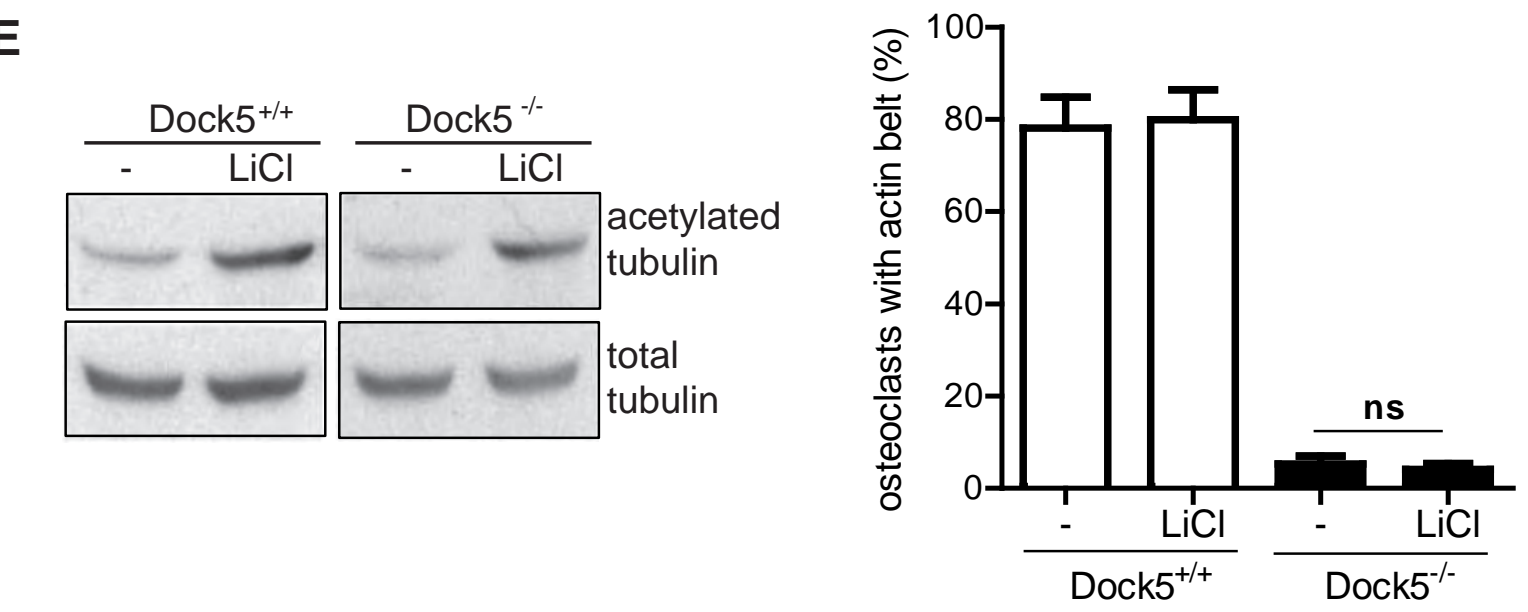


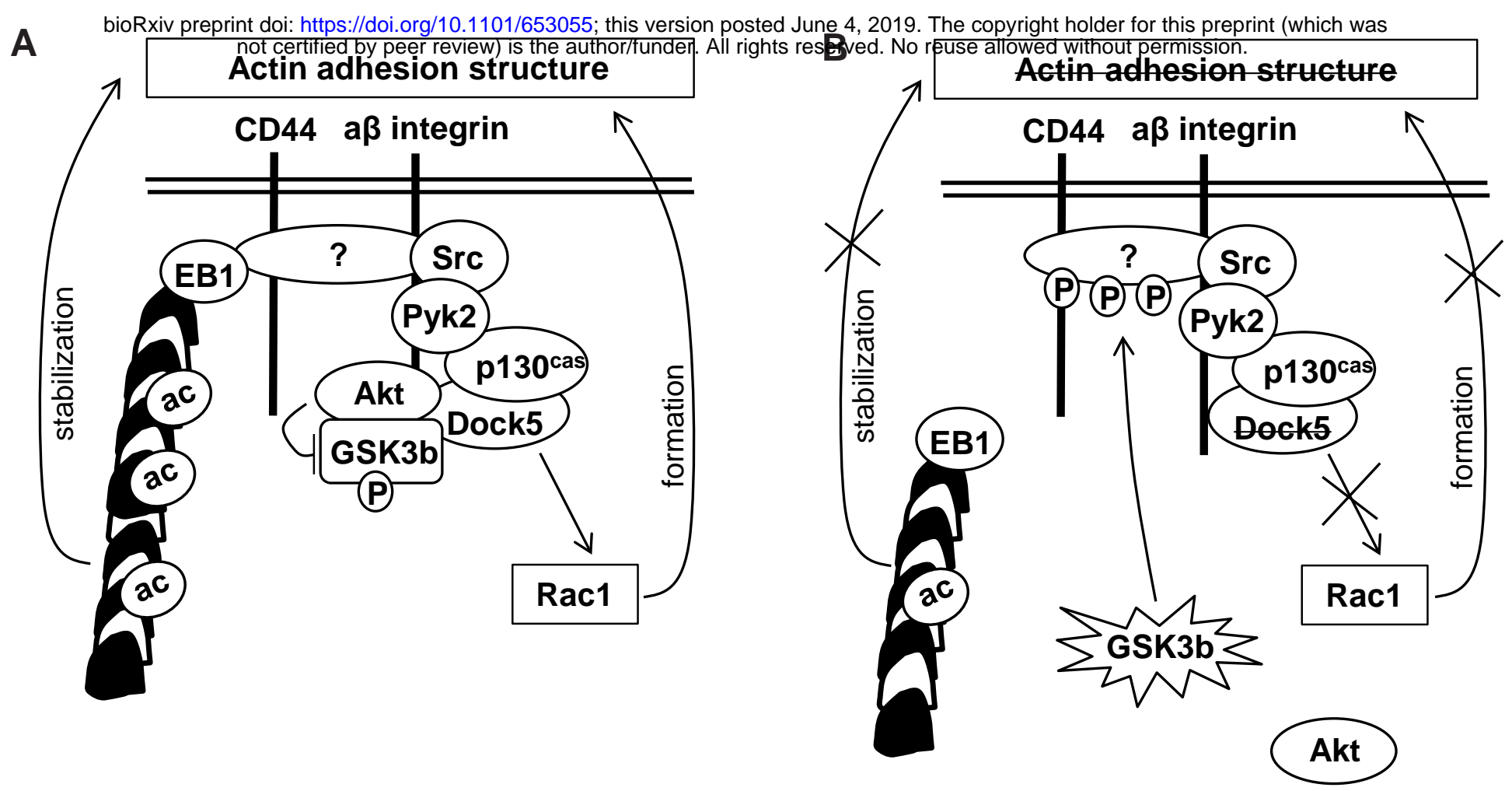

